\title{
Studies on Inducer Mediated Resistance Responses against Biological Fitness of Brevicoryne brassicae (Homoptera: Aphididae) on Brassica napus
}

\author{
Muhammad Wajid Javed ${ }^{1 *}$, Mansoor ul Hasan ${ }^{1}$, Muhammad Sagheer ${ }^{1}$ and Shahbaz Talib Sahi ${ }^{2^{*}}$ \\ ${ }^{1}$ Department of Entomology, University of Agriculture, Faisalabad, 038000, Pakistan \\ ${ }^{2}$ Department of Plant Pathology, University of Agriculture, Faisalabad 038000, Pakistan \\ *For correspondence: shahbazsahi@uaf.edu.pk; muhammadwajidjaved@gmail.com \\ Received 09 July 2020; Accepted 04 September 2020; Published 10 December 2020
}

\begin{abstract}
Cabbage aphid, Brevicoryne brassicae is among the notorious insect pests of Canola (Brassica napus) and other Brassica spp., with a reported loss of up to $75 \%$. It has gained resistance against conventional chemical insecticides. So, to activate inducer mediated plant resistance is among the workable solutions against this pest. Henceforth, inducer-mediated resistance based on categorizes of induced-resistance (IR), nutrient-deterrence (ND) and sulphur-integration (SI), was applied in 18 treatments. Their responses against aphid development period, reproduction time, progeny production, immature becoming adults, percent survival and mortalities, were noted-down. In the IR category, all the biological parameters were affected significantly by 1 $\mathrm{m} M$ ( 1 and $\mathrm{m} M$ should be in the same line) $\mathrm{m} M$ salicylic acid-T4 treatment, whereas in ND, silicon $50 \mathrm{~kg}$ ha ${ }^{-1}-\mathrm{T} 10$ was more effective. Likewise, during SI studies, bio-sulphur-T15 remained an efficient one. Overall, the developmental period of $B$. brassicae nymphs was delayed by $\mathrm{T} 10$ ( $\mathrm{Si} 50 \mathrm{~kg} \mathrm{ha}^{-1}$ ), followed by T4 (1 mM SA), while Compost-T16 expedited their development. Besides these, reproduction time was reduced at the most by T4, followed by T15. Aphid progeny production was again decreased significantly by T4 and T10, while T16 (Compost) presented the maximum progenies. Associatively, the least number of nymphs becoming adults were shown in T4, T10 followed by T7 (1 mM CA). The highest percent nymph survival was shown in T1 (control) and T16 (compost) with the highest nymph percent mortality in T4 and T7. Hence, salicylic acid, silicon, and bio-sulphur showed maximum effective resistance responses but in concentration-dependent manner. These findings can be used in future integrated pest management programs of aphids and other specialists on related hosts. (C) 2021 Friends Science Publishers
\end{abstract}

Keywords: Ammonium sulphate; Aphid; Bio-sulphur; Citric acid, Compost; Salicylic acid

\section{Introduction}

Canola, Brassica napus L. (Brassicaceae: Brassicales) is an important oilseed crop, ranked second among the edible oilseed in the world (Razaq et al. 2016; Kumar et al. 2017; Mohamed et al. 2020). Low contents of anti-nutritional ingredients like erucic acid and glucosinolates have made it worthwhile as eatable but simultaneously enhanced its vulnerability to insect pests (Mahmoud and Osman 2015; Nouri-Ganbalani et al. 2018; Sato et al. 2019; Chew 2020). Among such insect pests, cabbage aphid or Brevicoryne brassicae (L) (Homoptera: Aphididae) is a notorious pest causing huge yield loss. Losses are caused directly by sucking the cell sap and indirectly by transferring different types of viruses, which may result in complete crop failure (Saleem and Shah 2010; Razaq et al. 2016; Kumar et al. 2017). Moreover, the pest has a very high reproduction rate ( 43 generations/year) and adaptability in changing environmental conditions (Saleem and Shah 2010; Guilbaud and Khudr 2020; Javed and Qiu 2020; Li et al. 2020).
Synthetic chemical insecticides have been used against this pest, which are posing severe health concerns and also resulted in insecticide resistance development (Ahmad and Akhtar 2013; Li et al. 2020; Prince and Chandler 2020). Moreover, the waxy cuticle of the pest also reduces the effectiveness of applied insecticides (Ahmad and Akhtar 2013; Nouri-Ganbalani et al. 2018). This situation is thought-provoking and demands the researchers to evaluate alternative control measures that are safer to the environment and well-suited to human health (Javed and Qiu 2020; Prince and Chandler 2020).

In such a situation, inducer mediated plant resistance based on induced-resistance, nutrient-deterrence, and others, etc., are appeared to be a safer alternative tool (NouriGanbalani et al. 2018; Santos et al. 2018; Agathokleous et al. 2019). These may reduce not only the insect attack but also improve the growth, yield, and vigor of the crop ( $\mathrm{Li}$ et al. 2020; Rizzo et al. 2020). In induced-resistance (IR), plant bio-activators like salicylic, humic and jasmonic acids are working against insects and other stresses (Chen et al.

To cite this paper: Javed MW, MU Hasan, M Sagheer, ST Sahi (2021). Studies on inducer mediated resistance responses against biological fitness of Brevicoryne brassicae (Homoptera: Aphididae) on Brassica napus. Intl J Agric Biol 25:81-88 
2020; Khoshfarman-Borji et al. 2020; Naseem et al. 2020). Likewise, in nutrient-deterrence (ND), nutrients that can impact insect fitness and biology, are being utilized (Teixeira et al. 2017; Agathokleous et al. 2019; Boer et al. 2019). Here, the most important one is silicon ( $\mathrm{Si}$ ) that has also been found to be a critical in resistance induction against a variety of sucking insect pests, especially aphids (Teixeira et al. 2017; Boer et al. 2019; Rowe et al. 2020). Recently, ammonium sulphate (AS) has also been evaluated against herbivory on cauliflower (Agathokleous et al. 2019). Accordingly, sulphur-integration (in elemental-ES or bioBS formulations with soil amendments) against insect pests, is also needed to be evaluated due to the role of sulphur in the generation of various anti-insect compounds in brassica (Santos et al. 2018; Badenes-Pérez et al. 2020).

Although salicylic acid (SA) has been explored recently against the biological fitness of this pest on $B$. napus (Khoshfarman-Borji et al. 2020), however, there is no available information on inducer mediated responses of citric acid, ammonium sulphate and sulphur (bio/elemental formulations) against this pest. Moreover, in this study, citric acid and bio-sulphur are being used for the first time against any crop pest. In the main experiments, compost and ammonium sulphate are also being utilized for the first time, particularly against $B$. brassicae. Furthermore, these inducers were chosen regarding their field doses so that their performances can be suggested together for integrated pest and crop nutrient management programs.

Consequently, the current study was designed to check the responses/efficacies of these inducers against $B$. brassicae biological fitness comprising seven different resistance inducers in 18 treatments. Thus, their responses against insect development period, reproduction time, progeny production, nymphs becoming adults, nymph percent survival, and percent mortalities were noted.

\section{Materials and Methods}

\section{Insect and plant material}

Seeds of B. napus cv. Faisal Canola were sown in sterilized soil pots (top diameter $19 \mathrm{~cm}$ and height $15 \mathrm{~cm}$ ) filled with 3 $\mathrm{kg}$ of soil (sandy-clay-loam, NPK $0.05 \%, 7.47$, and 150 ppm). Environmental conditions were $21 \pm 5^{\circ} \mathrm{C}$ temperature, $65 \pm 5 \% \mathrm{RH}$, and photoperiod of 10:14 (L:D) h in the screen house. Various instars of $B$. brassicae were collected from Brassica crops (Brassica juncea, Brassica napus and Brassica oleracea). The insect culture was maintained on $B$. napus hosts, for more than 15 generations, at abovementioned conditions to homogenize the population (NouriGanbalani et al. 2018). The experiments proceeded on plants with 5-7 expanded leaves (Ahmed et al. 2018).

\section{Treatments and application}

Seven different resistance inducers in 18 treatments within
CRD design were applied via foliar and soil application methods, in potted plants of $B$. napus. Major inducer categories assigned were, induced-resistance (IR), nutrientdeterrence (ND) and sulphur-integration (SI) to generate plant resistance against $B$. brassicae. IR was contained of salicylic acid-SA and citric acid-CA, ND had silicon-Si and ammonium sulphate-AS. In contrast, SI experiments had elemental/bio-sulphur-ES/BS along with compost-Cp. These treatments and related information are presented in Table 1 and 2. For IR treatment preparation, salicylic acid and citric acid were dissolved in $0.01 \%$ ethanol and water, respectively, for the foliar spray to form $0,0.5$, and $1 \mathrm{~m} M$ solutions (Syeed et al. 2011). In $0 \mathrm{~m} M$ solution of SA and CA inducers, $0.01 \%$ ethanol and water, respectively were used. Silicon and ammonium sulphate were added to soil at the rate of 0,25 and $50 \mathrm{~kg} \mathrm{ha}^{-1}$. Elemental sulphur was applied alongside biosulphur and compost, in individual and integrated/combined manners. NPK was also applied according to the recommended field dose rate. The foliar spray was applied manually with the help of a hand sprayer (Type: Top gunmanual, Volume: $1000 \mathrm{~cm}^{3}$ ). While soil applications were made by mixing the treatments in the potting soil.

\section{Inducer mediated resistance responses against $B$. brassicae}

Screen house bioassays with multiple treatments were conducted to notice inducer mediated resistance responses against $B$. brassicae. Treated plants were provided with $B$. brassicae adult wingless female mothers of the same age groups. Potted plants with 5-7 expanded healthy leave, were chosen to check the responses of applied treatments. After introducing on each plant, the female mothers (FM1) were confined under clip cage covers $(6 \mathrm{~cm}$ diameter with a depth of $1.5 \mathrm{~cm}$ ). Each clip cage was referred to as one replication, and a total of 10 clip cages/replicates were followed per treatment. Then FM1 females were observed to lay young ones/nymphs (N1). After that, only one immature/nymph (N1) was allowed to stand per clip cage, and rests were removed. Later on, primary biological fitness responses were followed in sequence of developmental period of nymphs (N1) laid by FM1, reproduction time, next progeny production (N2), the immature becoming adults out of N2 progeny and percent survival of $\mathrm{N} 2$ generation with percent nymph mortality (Ahmed et al. 2018).

The developmental period was noted from first instar nymph till maturity (adult emergence), and reproduction time was considered from the time when the adult insects (N1) started laying young ones till the finishing of final laying; while progeny production was noticed by counting the number of nymphs per females. Likewise, nymphs/immature becoming adults (IBA) were the immature aphid numbers of $\mathrm{N} 2$ that survived till the adult stage. Their percent nymph survival was noticed by the nymphs survived in each treatment divided by total progeny in treatment and then multiplying the outcome with 100. 
Mitigation of Brassica Aphid Using Different Resistance Inducers / Intl J Agric Biol, Vol 25, No 1, 2021

Table 1: Inducer treatments and their nature

\begin{tabular}{llll}
\hline No. & Nature of treatments & No. & Nature of treatments \\
\hline T1 & Control $(\mathrm{Ct})$ & T10 & Silicon $50 \mathrm{~kg} \mathrm{ha}^{-1}$ \\
T2 & $0 \mathrm{~m} M$ salicylic acid & T11 & Ammonium sulphate (AS) $0 \mathrm{~kg} \mathrm{ha}^{-1}$ \\
T3 & $0.5 \mathrm{~m} M$ salicylic acid & T12 & Ammonium sulphate $25 \mathrm{~kg} \mathrm{ha}^{-1}$ \\
T4 & $1 \mathrm{~m} M$ salicylic acid & T13 & Ammonium sulphate $50 \mathrm{~kg} \mathrm{ha}^{-1}$ \\
T5 & $0 \mathrm{~m} M$ citric acid & T14 & Elemental sulphur (ES) \\
T6 & $0.5 \mathrm{~m} M$ citric acid & T15 & Bio-sulphur (BS) \\
T7 & $1 \mathrm{~m} M$ citric acid & T16 & Compost (Cp) \\
T8 & Silicon $0 \mathrm{~kg} \mathrm{ha}^{-1}(\mathrm{Si})$ & T17 & Elemental sulphur + compost \\
T9 & Silicon $25 \mathrm{~kg} \mathrm{ha}^{-1}$ & T18 & Bio-sulphur + compost \\
\hline
\end{tabular}

Table 2: Inducers, specifications and suppliers

\begin{tabular}{|c|c|c|}
\hline Inducers/nutrients & Specifications & Suppliers \\
\hline Salicylic acid & Purity $99.0 \%$ & Sigma Aldrich, MO, USA \\
\hline Citric acid & Purity $99.5 \%$ & Sigma Aldrich, MO, USA \\
\hline Ammonium sulphate & Nitrogen: $21 \%$, Sulphur: $24 \%$ & Engro Fertilizers, Pakistan \\
\hline Silicon $\left(\mathrm{SiO}_{2}\right)$ & $\begin{array}{l}\text { Silicon: } 46.7 \%, \mathrm{O}_{2}: 53.3 \% \text {, } \\
\text { Purity: } 99.9 \%\end{array}$ & Nanoshel, DE, USA \\
\hline Elemental sulphur & $\begin{array}{l}\text { (Bentonite) Sulphur: } 90 \pm \\
1.5 \%, \text { Inert: } 10 \pm 1.5 \%\end{array}$ & $\begin{array}{l}\text { Port Qasim, Karachi, } \\
\text { Pakistan }\end{array}$ \\
\hline Bio Sulphur & $\begin{array}{l}\text { Sulphur: } 70 \% \text {, NPK: } \sim 2.5 \% \text {, } \\
1.5 \%, 3 \%\end{array}$ & Dr. M. Naveed, ISES, UAF \\
\hline Compost $\left(\mathrm{g} \mathrm{kg}^{-1}\right)$ & $\begin{array}{l}\text { Carbon: } 210.5 \text {, Nitrogen: } \\
\text { 17.1, P: } 3.01 \text {, pH: } 6.43\end{array}$ & Dr. M. Naveed, ISES, UAF \\
\hline
\end{tabular}

Percent of nymph mortality was found by deducting survived insect percent out of 100 . Every observation was recorded daily until all the insects died (Bernardi et al. 2012; Nouri-Ganbalani et al. 2018).

\section{Data analysis}

In all three inducer mediated resistance experiments, data of each category with replicated ten times, were analyzed individually for IR, ND, and SI treatments. All the responses of treatments were averaged for mean values, and Fisher analysis was computed using the statistical software (Statistix 8.1, Analytical Software, Tallahassee). Significant differences among treatment means were separated by Tukey HSD test as a post-hoc parameter. Graphs were generated in Excel (MS Office, Version 2013). Statistical significance level of $P<0.05$ was taken in all assigned cases.

\section{Results}

\section{Induced-resistance (IR) responses against $B$. brassicae}

Statistically significant responses $(P<0.0001)$ were noticed among the induced-resistance responses for $B$. brassicae biological fitness (Fig. 1a-e). Insect development period (of N1 nymphs) was delayed significantly $\left(\mathrm{F}_{6,63}=14.7, P<\right.$ $0.0001)$ by the higher concentrations $(1 \mathrm{mM})$ of both SA and CA treatments (T3 and T4 in Table 1) contrasted to T1 control. However, SA was shown to be more effective in delaying the development to 9.96 days $(P<0.05)$ compared to 8.45 days in $\mathrm{CA}(P<0.001$; Fig. 1a). Likewise, reproduction time was also reduced the most by SA (9.40 days) compared to the CA (10.56 days) $\left(\mathrm{F}_{6,63}=12.4, P<0.0001\right)$ (Fig. 1b). Intermediate concentrations were also efficient, but SA was

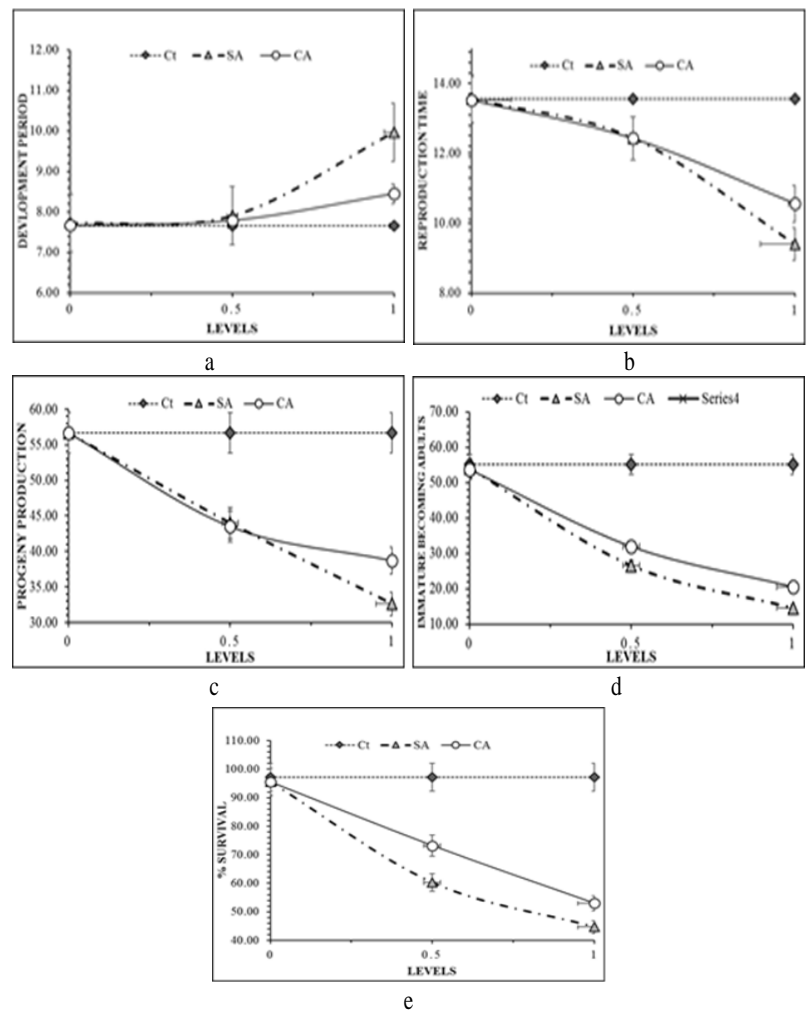

Fig. 1: Induced-resistance (IR) responses against different biological fitness parameters of $B$. brassicae a) Development period of nymphs N1 laid by females FM1 b) Reproduction time of N1 c) Progeny production (N2) d) Immature becoming adults (IBA) out of N2 progeny e) Percent survival of N2 generation

shown to be more responsive $(P<0.001)$.

Other parameters like progeny production (N2 nymphs), immature becoming adults (IBA), and N2 nymph percent survival was also disturbed (Fig. 1c-e). Statistically significant differences were noticed for progeny $\left(\mathrm{F}_{6,63}=6.90\right.$, $P<0.0001)$, IBA $\left(\mathrm{F}_{6,63}=12.4, P<0.0001\right)$ and percent nymph survived $\left(\mathrm{F}_{6,63}=13.7, P<0.0001\right)$. A high number of reduced progenies were observed in $1 \mathrm{mM} \mathrm{SA}(P<0.0001)$ with 32.60 nymphs followed by 38.70 nymphs in $1 \mathrm{mMCA}$ $(P<0.01)$ (Fig. 1c). Additionally, the least numbers of IBA were seen in similar treatments with 14.60 and 20.52 nymphs compared to control (55.10 nymphs). However, the difference among IR treatment means for IBA was nonsignificant (Fig. 1d). Percent nymph survival (Fig. 1e) was also appeared to be reduced to 44.62 and $52.97 \%$ in these treatments $(P<0.001)$ but again values of survived $B$. brassicae nymphs were not much different statistically in both T4 (1 mM SA) and T7 (1 mM CA) treatments (Table 1). Other treatments were less effective, depending upon their concentrations (T3 and T6) with significance at $P<$ $0.05, P<0.01$, when compared to the control T1 B. napus plants $(P<0.05)$. Additionally, nymph mortality was higher than $55.38 \%$ in T4 (1 mM SA) followed by $47.03 \%$ in T7 (1 $\mathrm{m} M \mathrm{CA}), 39.76 \%$ in $\mathrm{T} 3(0.05 \mathrm{~m} M \mathrm{SA})$ and $26.81 \%$ in $\mathrm{T} 6$ (0.05 mM CA), respectively (Fig. 4). 
Javed et al. / Intl J Agric Biol, Vol 25, No 1, 2021
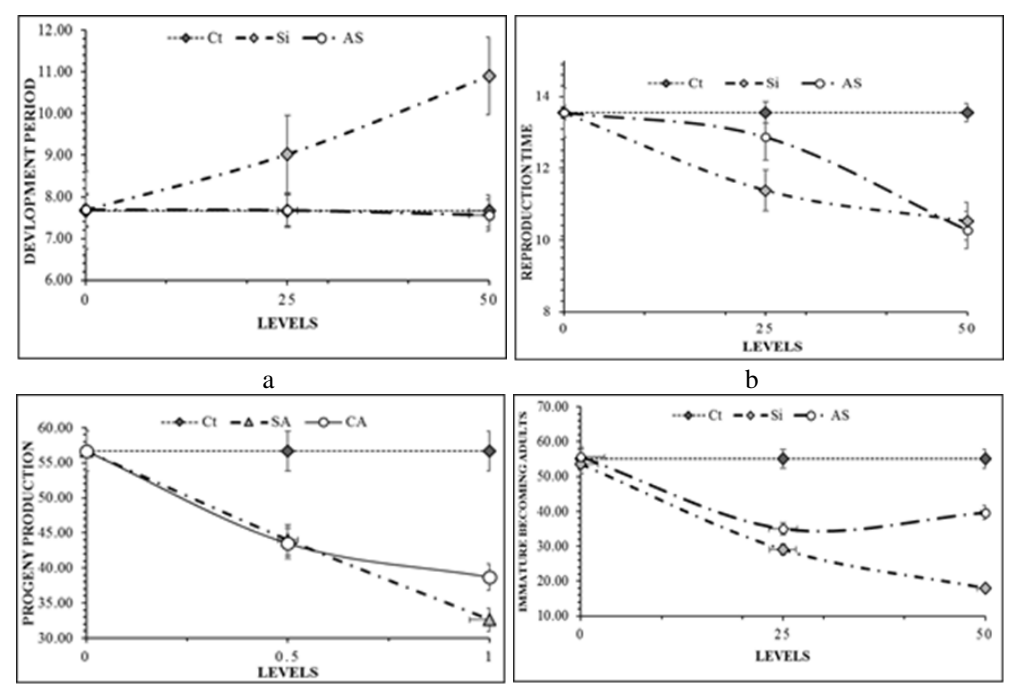

$\mathrm{b}$
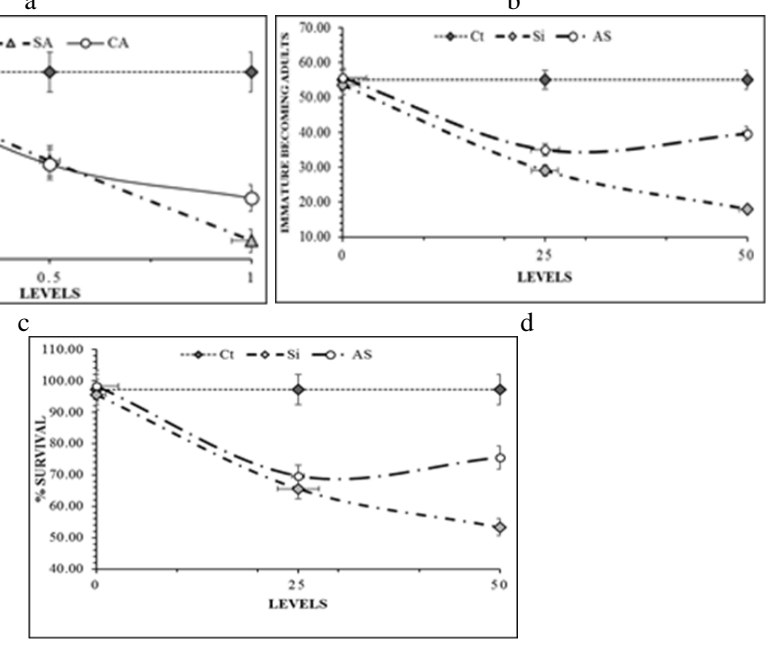

Fig. 2: Nutrient-deterrence (ND) responses against different biological fitness parameters of B. brassicae a) Development period of nymphs N1 laid by females FM1 b) Reproduction time of N1 c) Progeny production (N2) d) Immature becoming adults (IBA) out of N2 progeny e) Percent survival of N2 generation.
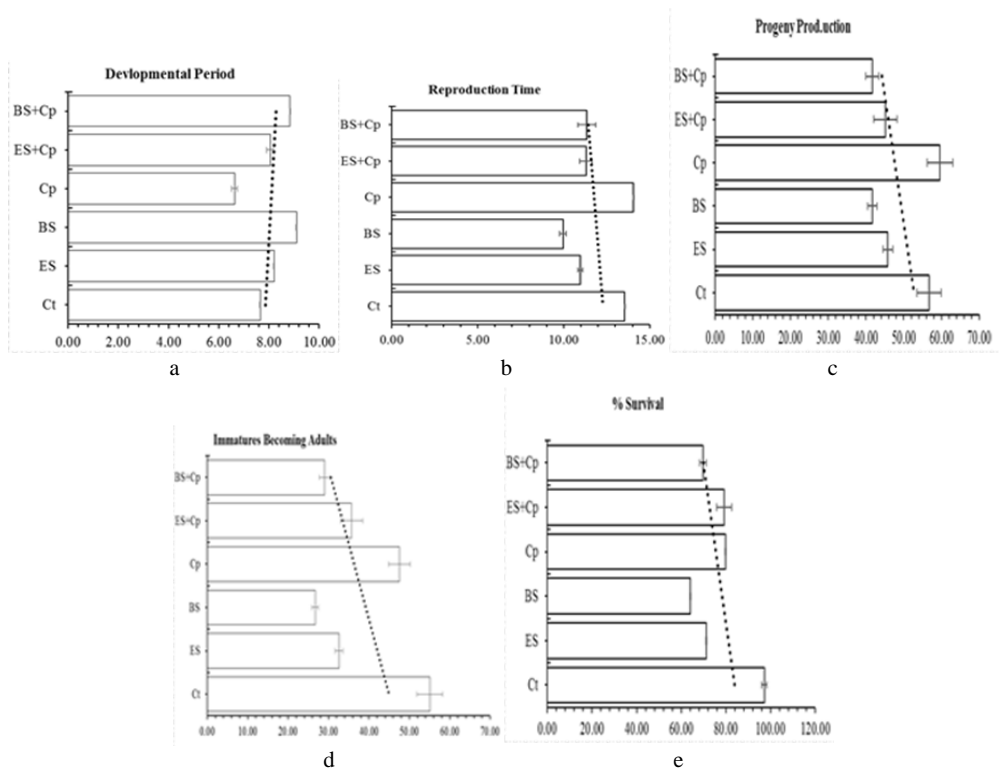

Fig. 3: Sulphur-integration (SI) against different biological fitness parameters of B. brassicae a) Development period of nymphs N1 laid by females FM1 b) Reproduction time of N1 c) Progeny production (N2) d) Immature becoming adults (IBA) out of N2 progeny e) Percent survival of $\mathrm{N} 2$ generation

\section{Nutrient-deterrence (ND) responses against B. brassicae}

Fisher variance values revealed significant difference among nutrients (silicon and ammonium sulphate at 0,25 and $50 \mathrm{~kg} \mathrm{ha}^{-1}$ ) treatments to influence and retard $B$. brassicae development, reproduction time, progeny 


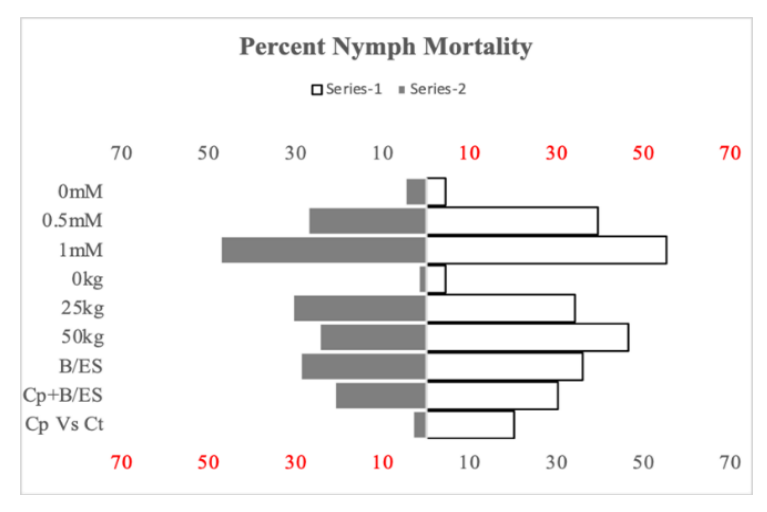

Fig. 4: Inducer mediated percent nymph mortality responses against $B$. brassicae. Series-1 (white bars) from top to bottom showing CA, AS, ES, ES + Cp, and Ct (Control) treatments. Series-2 (dark grey bars) from top to bottom are showing SA, Si, $\mathrm{BS}$, BS + Cp, and Cp treatments. Henceforth a horizontal bar chart is generated showing the comparisons of applied concentrations and doses as (left to right) SA vs. CA (in IR), Si vs. AS (in ND), and BS vs. ES (in SI) responses

production (nymphs/female), IBA and nymph survival $\left(\mathrm{F}_{6}\right.$, ${ }_{63}=28.6,16.1,6.94,16.7$ and 20.5) with $P<0.0001$ (Fig. 2a to 2e). In the ND category, doses and their responses remained efficient to increase the development period (N1 nymphs) (Fig. 2a) and decrease reproduction times (Fig. 2b). Si was recorded, apparently, more efficient to retard $B$. brassicae development by delaying to 10.90 days in T10 Si$50 \mathrm{~kg} \mathrm{ha}^{-1}$ contrasting AS treatments (7.68 days in T12, AS$25 \mathrm{~kg} \mathrm{ha}^{-1}$ ). Higher ammonium sulphate (T13, AS-50 kg ha$\left.{ }^{1}\right)$ dose was inefficient and reduced the development time to 7.56 days compared to control 7.66 days. Associatively, reproduction time continued to vary non-significantly and reduced by Si to 10.53 days in T10 and 10.28 days in T13, comparing against 13.55 days in T1 (Fig. 2d). While progeny production and immature becoming adults (IBA) were 34.10 in $\mathrm{T} 10$ to 50.30 nymphs in T12, contrasting to IBA numbers of 17.95 and 35.04 in the treatments of $50 \mathrm{~kg}$ ha $^{-1}$ silicon and $25 \mathrm{~kg} \mathrm{ha}^{-1}$ ammonium sulphate, respectively (Fig. 2c-d). Also, nymph survival was reduced proficiently under both treatments as $\mathrm{Si}$ (53.33\% in T10) and AS (69.62\% in T12), with statistical significance of $P<0.05$ and $P<0.01$ (Fig. 2e). Maximum nymph mortality (Fig. 4), was noticed in $50 \mathrm{~kg} \mathrm{ha}^{-1}$ silicon and $25 \mathrm{~kg} \mathrm{ha}^{-1}$ ammonium sulphate with 46.67 and $30.38 \%$, respectively.

\section{Sulphur-integration (SI) responses against B. brassicae}

Insect development $\left(\mathrm{F}_{5,54}=13.2, \quad P<0.0001\right)$ and reproduction time $\left(\mathrm{F}_{5,54}=11.7, P<0.0001\right)$ was retarded efficiently by all the treatments (Fig. 3-b). However, compost (T16) was shown to work negatively to reduce aphid development to 6.63 days and increase the reproduction time to 59.60 days. Effective responses for development were shown by bio-sulphur treatments (T15 and T18) with 9.10 and 8.84 days against reproduction time of 9.96 and 11.33 , respectively.

Number of nymphs/female (progeny) $\left(\mathrm{F}_{5,54}=3.64\right.$, $\mathrm{P}=0.0066)$ and IBA values $\left(\mathrm{F}_{5,54}=11.7, P<0.0001\right)$ were 41.70 (BS) and 45.80 (ES) nymphs, whereas 26.72 (BS) and 32.64 (ES) immature were transferring to adult stages. Among all such treatment means of SI, non-significant responses $(\mathrm{P}=0.05)$ were noted. However, nymph survival $\left(\mathrm{F}_{5,54}=33.9, P<0.0001\right)$ was observed higher in T16 (Cp) to $79.81 \%$ and lower in T15 (BS) treatments to $64.10 \%$. However, a significant difference among treatment means was observed at $P<0.05$ (for BS), $P<0.01$ (ES and BS + $\mathrm{Cp}$ ), and $P<0.001$ (ES $+\mathrm{Cp}$ and $\mathrm{BS}+\mathrm{Cp}$ ), respectively. Mortality percent of N2 nymphs remained higher to $35.90 \%$ in BS-T15 and $30.24 \%$ in BS + Cp (T18) sulphurintegration treatments (Fig. 4). While discussing mean values obtained in the SI category, all the applied treatments were useful; however, integration of sulphur with compost exhibited greater impacts compared to single ones.

\section{Discussion}

Inducer mediated resistance responses against insect pests have been shown as an alternative tool to synthetic insecticides (Nouri-Ganbalani et al. 2018; Serteyn et al. 2020). In the current study, inducer mediated plant resistance, centered on induced-resistance, nutrientdeterrence, and sulphur-integration, has shown its tremendous potential to mitigate aphid pest as a nontoxic substitute (Teixeira et al. 2017; Agathokleous et al. 2019; Khoshfarman-Borji et al. 2020). For the first time, citric acid, ammonium sulphate, bio-sulphur, and compost have been recorded for their anti-insect potential. These have not only lessened the insect occurrence but also provided supportable outcomes for increasing the plant defenses (Boer et al. 2019; Li et al. 2020; Rizzo et al. 2020).

In case of induced-resistance, foliar application of salicylic/citric acid and related compounds have been shown to invigorate the built-in plant defenses against invaders, called induced systemic resistance (Züst and Agrawal 2016; Nam et al. 2020; Serteyn et al. 2020). Previously only bioactivators/phytohormones (Benzo-thiadiazole and Jasmonic acid) have been employed to reduce pest abundance (Selig et al. 2016; Nouri-Ganbalani et al. 2018). But they are costly enough to restrict their field application practically (Dhandhukia and Thakkar 2007). Also, they may antagonize plant defense against the specialist pest due to issues in defensive signaling crosstalk (Schmiesing et al. 2016; Li et al. 2019; Irigoyen et al. 2020; Ma et al. 2020). As $B$. brassicae is also a specialist pest (Nouri-Ganbalani $e t$ al. 2018), thus some alternative bio-activators such as SA and CA suitable against such pest, are needed to explore.

Our work has suggested the pivotal associations of using such alternative cost-efficient and defense-effective inducers that can inflict injuries to pest and their progenies. We used salicylic and citric acids, with different levels of foliar concentrations, to induce resistance against $B$. 
brassicae. Important outcomes were found, showing that SA and CA were not only helpful for reducing $B$. brassicae development period and reproduction times but also its progenies and nymph percent survival was reduced significantly. Insect developmental and reproduction time may be retarded due to the effect of defense genes $(P R$ and $P I N)$ and metabolites that are shown to be elicited in plants by IR treatments (Studham and MacIntosh 2013; Ma et al. 2020; Irigoyen et al. 2020). These metabolites are usually glucosinolates, phenolics, and some other flavonoids (Studham and MacIntosh 2013; Khoshfarman-Borji et al. 2020).

B. brassicae was also able to produce the least number of next-generation progenies and IBA with lesser percent survival compared to control plants. This was happened since $B$. brassicae reproduction time was shortened, thus lesser numbers of nymphs/female were produced in a successive generation. Additively, less number of immature became adults with the least percent survival. The similar responses have been portrayed by Nouri-Ganbalani et al. (2018) and Khoshfarman-Borji et al. (2020), who have described that aphid offspring become less viable after feeding on plants under IR treatments (Khoshfarman-Borji et al. 2020) showed the effectiveness of SA and humic acid induced-resistance implicating different biological fitness attributes of B. brassicae aphids on B. napus with similar results.

Work on other plants like wheat, barley, soybean, and Brassica spp., has shown the effectiveness of inducedresistance against bio-fitness attributes of Myzus persicae and Lipaphis spp. aphids (Chaman et al. 2003; Studham and MacIntosh 2013; Mahmoud and Osman 2015; Sun et al. 2016; Nouri-Ganbalani et al. 2018). Its underlying mechanism involves the activation of defense transcriptional machinery, against aphid infestations (Studham and MacIntosh 2013). Associatively, to reference further, decrements in these biological parameters, have also been attributed to diverse packaging of secondary range biochemicals that can restrict phloem uptake and nutrient digestion in aphids (Chaman et al. 2003; Studham and MacIntosh 2013; Khoshfarman-Borji et al. (2020).

Silicon and ammonium sulphate, although not appeared much in pest reduction studies, however, their efficiencies to activate plant built-in defense machinery, are giving insights to use them as pest control implements (Teixeira et al. 2017; Boer et al. 2019). Henceforth, as per assumption, soil routed $\mathrm{Si}$ and $\mathrm{AS}$ showed better results to affect $B$. brassicae developmental and reproductive performances in dose-dependent manner (Fig. 2a-e). In the ND category, compared to AS, Si has been recorded to delay insect development both in 25 and $50 \mathrm{~kg} \mathrm{ha}^{-1}$ doses, but it was evident that doubling the dose $\left(50 \mathrm{~kg} \mathrm{ha}^{-1}\right)$ is not retarding the pest developmental time twice as expected. The response may be occurred due to excessive $\mathrm{Si}$ fertilization that renders the plant inefficient to optimize its defense system further (Rowe et al. 2020; Amsterdam
2020). B. brassicae reproduction time, progeny, and adults appearing from these progenies (IBA) along with their percent survival were also affected significantly. Delay in development and reduction in reproducing days to give next progenies are responsible for lesser nymphs to become adults with the least viable generation. Such implications of Si for aphid have been considered to be associated with reduced food intake in offspring as $\mathrm{Si}$ cements the plant tissues against mechanical injuries (Alhousari and Greger 2018).

Besides, least nutrient digestibility indices with severe impact on aphid growth and biological performances have also been mentioned (Alhousari and Greger 2018). Boer et al. (2019) have exhibited Si effectiveness to retard nutrient digestibility in sap-sucking and leaf chewing insect pests due to coagulation and fabrication of food materials. Moise et al. (2019) mentioned the involvement of plant nutrient status and insect physiology to impede insect growth and digestion indices under Si application.

Likewise, mentioned biological fitness parameters were also impaired in AS application. However, AS in 25 $\mathrm{kg} \mathrm{ha}^{-1}$ was working more competently, contrasting to 50 $\mathrm{kg}^{-1}$. Similar dose responses were shown for progeny production, IBA, and nymph survival. The efficient performance of AS $25 \mathrm{~kg}$ may be associated with higher production of defense compounds due to active presence of sulphur ingredient. Sulphur is thought to work and generate efficient sources of glucosinolates to deter the aphids on brassica crops (Badenes-Pérez et al. 2020; Santos et al. 2018). Also, Agathokleous et al. (2019) have revealed the bio-inhibitory impacts of AS for insects on brassica plants even under ozone pollution. But this effect may be altered under excessive or high AS doses, especially for insect defense (Sabino et al. 2018).

Furthermore, both soil dose responses at $25 \mathrm{~kg}$ and 50 $\mathrm{kg}$ were comparatively more efficient against control treatment plants. But reduced responses of higher AS dose $(50 \mathrm{~kg})$, was attributive of increased plant nitrogen content. Such higher nitrogen contents can favour the insect pest (Santos et al. 2018; Agathokleous et al. 2019). This valueadded improvement in plant nitrogen levels has been revealed by Syeed et al. (2011) due to increments in plant root areas that were noticed under higher nitrogen fertilizer doses. Thus, the inefficiency of $50 \mathrm{~kg}$ AS over to $25 \mathrm{~kg}$, as suggested from enhanced feeding and reproduction of $B$. brassicae on AS treated plants was connected with higher plant nitrogen contents.

Sulphur-integration with compost in elemental and bio-sulphur formulations against $B$. napus aphid was assessed due to the role of sulphur in the production of different anti-insect defense complexes (phenolics, flavonoids, and glucosinolates) in brassica plants (Santos et al. 2018; Badenes-Pérez et al. 2020). In the present study, sulphur results were more operative and augmentative for bio-formulations to restrict aphid biological parameters. Moreover, in comparison to elemental sulphur, bio-sulphur 
was performing better with compost combinations. Insect developmental period, reproduction, and progeny production, along with IBA and nymph survival and mortalities, were all forceful to generate resistance responses in sulphur bio-formulation (BS).

BS has performed proficiently to impede B. brassicae bio-fitness compared to elemental formulations. This activity of $\mathrm{BS}$ has been produced under microbial decomposition, which, in turn, has exhibited to make the sulphur available efficiently to plants (Kumar et al. 2018; Singh et al. 2020). Moreover, the presence of beneficial microbial fauna in BS may have increased the plant capabilities to detoxify redox species under stress responses. Besides these, plant physiology and volatile organic compounds were also recorded to improve by microbial activities, thus, to reinforce plant defense (Raza and Shen 2020). Furthermore, higher contents of sulphur ( $90 \pm 1.5 \%)$ in elemental formulation-ES compared to BS (70\% sulphur), may also render ES treatment less valid. Higher sulphur doses may also sometime show implications to plant growth and defense mechanism. Also, non-availability of microbial fauna may serve as another reason to supply sulphur inefficiently to plants (Singh et al. 2020).

Concisely, the sulphur treatments, both alone and integrated, were efficient. However, compost worked negatively to mitigate the pest. Most of the time, positive relations to improve $B$. brassicae reproduction and development were recorded for compost, compared to the control plants. The responses may occur because of the presence of high proportions of nitrogen $\left(17.1 \mathrm{~g} \mathrm{~kg}^{-1}\right)$ in compost to favor the aphid. Nonetheless, higher $B$. brassicae mortalities compared to the control plants were also there. But this may be attributive of the presence of phosphorous (3.01 $\mathrm{g} \mathrm{kg}^{-1}$ ) in compost. Phosphorous has been documented to work negatively against the biological fitness characteristics of different insect pests (Cease et al. 2016). Other reinforcing arguments were manifested by the fact that sulphur has more roles in the production of anti-aphid glucosinolates (Rehman et al. 2013). Additively, increased uptake of essential nutrients (Chaman et al. 2003; Sun et al. 2016; Syeed et al. 2011), is also mentioned under sulphur application to enhance plant resistance against the pest.

\section{Conclusion}

The present studies have given a clear view for inducer mediated resistance under different inducer categories to be functionally operative to reduce the biological fitness of $B$. brassicae. All crucial parameters like developmental period, reproduction times, progeny production, immature becoming adults, and percent survival was decreased significantly. However, the type and concentration of inducers were of real concern. Additionally, increasing the concentration of inducers may be effective against insect pests, but phytotoxicity must be considered in all orientations. Molecular/genetics-based research is also being suggested to explore the underlying mechanism of such resistance responses. Moreover, field-level applications and evaluations are also being recommended for further investigations.

\section{Acknowledgment}

We acknowledge the role of ORIC (UAF), and HEC to facilitate the research.

\section{Author Contributions}

Muhammad Wajid Javed, Mansoor ul Hasan, Muhammad Sagheer and Shahbaz Talib Sahi planned the experiments. Mansoor ul Hasan and Muhammad Sagheer designed the experiment. Muhammad Wajid Javed conducted the experiments, and Mansoor ul Hasan and Shahbaz Talib Sahi performed statistical analysis. Muhammad Wajid Javed and Mansoor ul Hasan wrote the manuscript.

\section{References}

Agathokleous E, Y WaiLi, G Ntatsi, K Konno, CJ Saitanis, M Kitao, T Koike (2019). Effects of ozone and ammonium sulfate on cauliflower: Emphasis on the interaction between plants and insect herbivores. Sci Tot Environ 659:995-1007

Ahmad M, S Akhtar (2013). Development of insecticide resistance in field populations of Brevicoryne brassicae (Hemiptera: Aphididae) in Pakistan. J Econ Entomol 106:954-958

Ahmed N, HLC Darshanee, WY Fu, XS Hu, Y Fan, TX Liu (2018) Resistance of seven cabbage cultivars to green peach aphid (Hemiptera: Aphididae). J Econ Entomol 111:909-916

Alhousari F, M Greger (2018). Silicon and mechanisms of plant resistance to insect pests. Plants 7:33-41

Amsterdam SV (2020). Synergistic defensive effects of silicon and Epichloë endophytes on insect pests of agricultural grasses in New Zealand. M.Sc. Thesis. The University of Waikato, New Zealand

Badenes-Pérez FR, J Gershenzon, DG Heckel (2020). Plant glucosinolate content increases susceptibility to diamondback moth (Lepidoptera: Plutellidae) regardless of its diet. J Pest Sci 93:491-506

Bernardi D, MS Garcia, M Botton, DE Nava (2012). Biology and fertility life table of the green aphid Chaetosiphon fragaefolli on strawberry cultivars. J Ins Sci 12:28-35

Boer C, M Sampaio, H Pereira (2019). Silicon-mediated and constitutive resistance to Rhopalosiphum maidis (Hemiptera: Aphididae) in corn hybrids. Bull Entomol Res 109:356-364

Cease AJ, M Fay, JJ Elser, JF Harrison (2016). Dietary phosphate affects food selection, post-ingestive phosphorus fate, and performance of a polyphagous herbivore. J Exp Biol 219:64-72

Chaman ME, SV Copaja, VH Argandoña (2003). Relationships between salicylic acid content, phenylalanine ammonia-lyase (PAL) activity, and resistance of barley to aphid infestation. J Agric Food Chem 51:2227-2231

Chen L, X Zhao, J Wu, Y He, H Yang (2020). Metabolic analysis of salicylic acid-induced chilling tolerance of banana using NMR. Food Res Intl 128:10-18

Chew SC (2020). Cold-pressed rapeseed (Brassica napus) oil: Chemistry and functionality. Food Res Intl 131:89-97

Dhandhukia P, V Thakkar (2007). Standardization of growth and fermentation criteria of Lasiodiplodia theobromae for production of jasmonic acid. Afr J Biotechnol 6:19-27

Guilbaud C, M Khudr (2020). Disturbance and competition drive diversity effects in cabbage-aphid-onion systems with intra-specific genetic variation. Bull Entomol Res 110:123-135 
Irigoyen ML, DC Garceau, A Bohorquez-Chaux, LAB Lopez-Lavalle, L Perez-Fons, PD Fraser, LL Walling (2020). Genome-wide analyses of cassava Pathogenesis-related (PR) gene families reveal core transcriptome responses to whitefly infestation, salicylic acid and jasmonic acid. BMC Genomics 21:93-99

Javed K, D Qiu (2020). Protein elicitor PeBL1 of Brevibacillus laterosporus enhances resistance against Myzus persicae in tomato. Pathogens 9:57-65

Khoshfarman-Borji H, MP Yali, M Bozorg-Amirkalaee (2020). Induction of resistance against Brevicoryne brassicae by Pseudomonas putida and salicylic acid in canola. Bull Entomol Res 110:1-14

KumarS, Y Singh, S Singh, R Singh (2017). Physical and biochemical aspects of host plantresistance to mustard aphid, Lipaphis erysimi (Kaltenbach) in rapeseed-mustard.Arthropod-Plant Interact 11:551-559

Kumar U, P Panneerselvam, VV Gupta, M Manjunath, P Priyadarshinee, A Sahoo, SR Dash, M Kaviraj, K Annapurna (2018). Diversity of sulfur-oxidizing and sulfur-reducing microbes in diverse ecosystems. In: Advances in Soil Microbiology: Recent Trends and Future Prospects, pp:65-89. Adhya T, B Lal, B Mohapatra, D Paul, $S$ Das (Eds.). Springer, Singapore

Li W, YC Zhu, F Li, Y He (2020). In silico discovery of genes encoding insecticide targets and detoxifying enzymes in Brevicoryne brassicae and Lipaphis erysimi. J Asia-Pac Entomol 23:159-166

Ma F, X Yang, Z Shi, X Miao (2020). Novel crosstalk between ethylene-and jasmonic acid-pathway responses to a piercing-sucking insect in rice. New Phytol 225:474-487

Mahmoud M, M Osman (2015). Management of cabbage aphid, Brevicoryne brassicae $\mathrm{L}$. on canola crop using neonicotinoids seed treatment and salicylic acid. J Phytopathol Pest Manage 2:9-17

Mohamed IA, N Shalby, C Bai, M Qin, RA Agami, K Jie, B Wang, G Zhou (2020). Stomatal and photosynthetic traits are associated with investigating sodium chloride tolerance of Brassica napus $\mathrm{L}$. cultivars. Plants 9; Article 62

Moise ER, JN McNeil, SE Hartley, HA Henry (2019). Plant silicon effects on insect feeding dynamics are influenced by plant nitrogen availability. Entomol Exp Appl 167:91-97

Nam TD, YA Abdulle, K Javed, T Sokea, D Qiu (2020). A Novel Protein Elicitor PevL1, from Verticillium lecanii 2, induces systemic resistance against bean aphid (Megoura Japonica Matsumura) in Phaseolus vulgaris L. Intl J Plant Anim Environ Sci 10:81-94

Naseem M, M Anwar-ul-Haq, J Akhtar, MJ Jaskani (2020). Effect of exogenous application of salicylic acid and sodium nitroprusside on maize under selenium stress. Pak J Agric Sci 57:150-158

Nouri-Ganbalani G, E Borzoui, M Shahnavazi, A Nouri (2018). Induction of resistance against Plutella xylostella (L.) (Lep.: Plutellidae) by jasmonic acid and mealy cabbage aphid feeding in Brassica napus L. Front Physiol 9; Article 859

Prince G, D Chandler (2020). Susceptibility of Myzus persicae, Brevicoryne brassicae and Nasonovia ribisnigri to fungal biopesticides in laboratory and field experiments. Insects 11; Article 55

Raza W, Q Shen (2020). Volatile organic compounds mediated plantmicrobe interactions in soil. In: Molecular Aspects of Plant Beneficial Microbes in Agriculture, pp:209-219. Sharma V, R Salwan, LKT Al-Ani (Eds.). Academic Press, USA

Razaq M, M Farooq, G Abbass, M Aslam, M Rehman, M Iqbal (2016). Is reduction in yield potential of some brassicaceous species due to aphid infestation associated with the changes in stomatal factors of photosynthesis? Pak J Bot 48:1665-1671
Rehman H, Q Iqbal, M Farooq, A Wahid, I Afzal, SMA Basra (2013). Sulphur application improves the growth, seed yield and oil quality of canola. Acta Physiol Plantarum 35:2999-3006

Rizzo E, T Sherman, P Manosalva, SK Gomez (2020). Assessment of local and systemic changes in plant gene expression and aphid responses during potato interactions with arbuscular mycorrhizal fungi and potato aphids. Plants 9 ; Article 82

Rowe RC, P Trębicki, AN Gherlenda, SN Johnson (2020). Cereal aphid performance and feeding behaviour largely unaffected by silicon enrichment of host plants. J Pest Sci 93:41-48

Sabino PHDS, FR Júnior, GA Carvalho, JR Mantovani (2018). Nitrogen fertilizers and occurrence of Leucoptera coffeella (Guérin-Mèneville $\&$ Perrottet) in transplanted coffee seedlings. Cof Sci 13:410-414

Saleem MA, HA Shah (2010). Applied Entomology: A Pakistan Perspective. Pak Book Empire, Lahore, Pakistan

Santos N, N Teixeira, J Valim, E Almeida, M Oliveira, W Campos (2018). Sulfur fertilization increases defense metabolites and nitrogen but decreases plant resistance against a host-specific insect. Bull Entomol Res 108:479-486

Sato Y, A Tezuka, M Kashima, A Deguchi, R Shimizu-Inatsugi, M Yamazaki, KK Shimizu, AJ Nagano (2019). Transcriptional variation in glucosinolate biosynthetic genes and inducible responses to aphid herbivory on field-grown Arabidopsis thaliana. Front Genet 10; Article 787

Schmiesing A, A Emonet, C Gouhier-Darimont, P Reymond (2016). Arabidopsis MYC transcription factors are the target of hormonal salicylic acid/jasmonic acid cross talk in response to Pieris brassicae egg extract. Plant Physiol 170:2432-2443

Selig P, S Keough, VJ Nalam, P Nachappa (2016). Jasmonate-dependent plant defenses mediate soybean thrips and soybean aphid performance on soybean. Arthropod-Plant Interact 10:273-282

Serteyn L, C Quaghebeur, M Ongena, N Cabrera, A Barrera, MA MolinaMontenegro, F Francis, CC Ramírez (2020). Induced systemic resistance by a plant growth-promoting rhizobacterium impacts development and feeding behavior of aphids. Insects 11:234-241

Singh D, R Prasanna, V Sharma, MVS Rajawat, S Nishanth, AK Saxena (2020). Prospecting plant-microbe interactions for enhancing nutrient availability and grain biofortification. In: Wheat and Barley Grain Biofortification, pp:203-228. Gupta OP, V Pandey, S Narwal, P Sharma, S Ram, GP Singh (Eds.). Woodhead Publishing, UK

Studham ME, GC MacIntosh (2013). Multiple phytohormone signals control the transcriptional response to soybean aphid infestation in susceptible and resistant soybean plants. Mol Plant Interact 26:116-129

Sun Y, X Xia, J Jiang, S Chen, F Chen, G Lv (2016). Salicylic acid-induced changes in physiological parameters and genes of the flavonoid biosynthesis pathway in Artemisia vulgaris and Dendranthema nankingense during aphid feeding. Genet Mol Res 15:1-15

Syeed S, NA Anjum, R Nazar, N Iqbal, A Masood, NA Khan (2011). Salicylic acid-mediated changes in photosynthesis, nutrients content and antioxidant metabolism in two mustard (Brassica juncea L.) cultivars differing in salt tolerance. Act Physiol Plantarum 33:877-886

Teixeira NC, JOS Valim, WG Campos (2017). Silicon-mediated resistance against specialist insects in sap-sucking and leaf-chewing guilds in the Si non-accumulator collard. Entomol Exp Appl 165:94-108

Züst T, AA Agrawal (2016). Mechanisms and evolution of plant resistance to aphids. Nat Plants 2; Article 15206 